Article

\title{
Experimental Investigation of the Flow Mechanisms and the Performance Change of a Highly Loaded Axial Compressor Stage with/without Stator Hub Clearance
}

\author{
Baojie Liu ${ }^{1,2,3}$, Ying Qiu ${ }^{1}$, Guangfeng An ${ }^{1,2,3, *(1)}$ and Xianjun Yu ${ }^{1,2,3}$ (D) \\ 1 School of Energy and Power Engineering, Beihang University, Beijing 100191, China; \\ liubj@buaa.edu.cn (B.L.); 2452416@163.com (Y.Q.); yuxj@buaa.edu.cn (X.Y.) \\ 2 National Key Laboratory of Science and Technology on Aero-Engine Aero-Thermodynamics, \\ Beihang University, Beijing 100191, China \\ 3 Collaborative Innovation Center of Advanced Aero-Engine, Beihang University, Beijing 100191, China \\ * Correspondence: guangfeng@buaa.edu.cn; Tel.: +86-010-8231-6419
}

Received: 24 October 2019; Accepted: 25 November 2019; Published: 27 November 2019

\begin{abstract}
Three-dimensional corner separation is common in axial compressors, which can lead to large flow loss and blockage especially when it evolves into the corner stall (open separation). In this paper, the evolution of the three-dimensional flow structures inside a cantilevered stator of a 1.5 stage low-speed highly loaded axial compressor as the stator hub clearance varies, and its effect on the whole compressor performance are investigated experimentally. Firstly, when the stator hub is sealed, the hub corner stall will occur at small mass flow rate conditions. Then, when a very small stator hub clearance is introduced, the leakage flow tends to strengthen the hub corner separation at large mass flow rate conditions and prompts the occurrence of hub corner stall as the mass flow rate decreases. This is mainly caused by the fact that the leakage flow has relatively low energy due to the viscosity effect in the clearance and large flow loss generation as the clearance flow comes across and mixes with the transverse secondary flow. Finally, when the stator hub clearance increases, the effect of the flow viscosity becomes very weak and could be ignored, so the enhanced leakage flow can suppress the transverse migration of the low energy flow near the hub, and the hub corner separation at large mass flow rate conditions could be weakened and the hub corner stall at small mass flow rate conditions could be removed or delayed. As the stator hub clearance varies, the flow structures inside the stator passage could be summarized into five typical flow structures, and this is closely associated with the performance of the compressor.
\end{abstract}

Keywords: cantilevered stator; corner separation; corner stall; leakage flow

\section{Introduction}

Three-dimensional corner separation is an inherent flow feature in axial compressors, the induced flow blockage and loss of which can deteriorate the compressor performance. In particular, when the corner separation turns into a corner stall, large backflow will occur at the corner surrounded by the blade suction surface and the end wall [1,2], and the compressor performance will decrease rapidly $[3,4]$. Hence, to suppress the corner separation, especially to delay the occurrence of the corner stall, many active and passive control techniques has been proposed, like the air aspiration [5-8], air blowing [1,9-11], vortex generators [6,12], three-dimensional blade stacking $[2,13,14]$ and so on, while the cantilevered stator is still an efficient technique to be frequently used in practice.

Early in 1954, Dean [15] pointed out that the leakage flow that generates from the clearance between the blade tip and the end wall in the cantilevered stator has the opposite flow direction to the 
secondary flow in the wall boundary layer, hence, it can suppress the migration of the low energy flow to accumulate in the corner surrounded by the blade suction surface and the end wall and the corner separation is weakened consequently. This conclusion was then verified by Lakshminarayana and Horlock [16-18], who conducted some experiments in the linear cascade and put forward that there exists an optimum clearance size that makes the flow loss to be the minimum.

Since then, many studies about the flow inside the cantilevered stator have been conducted, and the investigated objects mainly focused on two topics. The first one is the flow mechanism of the interaction between the leakage flow and the corner separation. For example, Dean [15], Lakshminarayana and Horlock [18], Singh and Ginder [19], Lee, et al. [20], and George, et al. [21] thought it is the suppression of the migration of the low energy flow by the leakage flow that weakens the corner separation, while Gbadebo, et al. [22] pointed out that it is the suppression of the horseshoe vortex in the leading edge that causes the removal of the corner separation, and Dong, et al. [23] considered that the suppression of corner separation is mainly caused by the mixing of the high energy leakage flow with the low energy flow in the corner. The second one is the effect of the clearance size on the compressor or the cascade performance. For example, Lakshminarayana and Horlock [18] and Peacock [24] both found that there exists an optimum clearance size that makes the performance of the compressor cascade to be the best and Lakshminarayana and Horlock [18] pointed out that this only happens when the strength of the leakage flow and the secondary flow are comparable and they can just cancel out; Sakulkaew, et al. [25] also found that there is an optimum clearance at the rotor tip in an industrial gas turbine, and proposed that this phenomenon is mainly caused by the decrease of clearance flow mixing loss and increase of viscous loss in the tip clearance with the decrease of tip clearance size; in addition, Dong, et al. [23] found that the leakage flow can eliminate corner separation at the stator hub, and improve the compressor performance, which has been verified by Wennerstrom [26], and McDougall [27] at the rotor tip, while Gbadebo, et al. [22] revealed that the clearance flow tends to strengthen the corner separation when the clearance size is very small.

From the discussion above it can be seen that there are still some controversies on the mechanism of the suppression of the corner separation by the leakage flow, and the effect of stator hub clearance on the compressor performance is not consistent yet. Hence, in this paper, a detailed experimental investigation is conducted in a cantilevered stator of a highly loaded axial compressor, at varies stator hub clearance sizes, i.e., $0 \%$ (sealed), $0.25 \%, 0.5 \%$, and $1 \%$ blade height. Both the oil-flow visualization and the five-hole probe are used to measure the complicated flow structures. To have a clear cognition on the 3D separating flow in this stator, the evolution of the 3D flow structures inside the stator at zero clearance is discussed firstly, then the effect of stator hub clearance size on 3D corner separation inside the stator passage and on the compressor performance are comprehensively analyzed at three typical mass flow rate conditions, including the design condition (DE), the peak static pressure rise condition (PP), and the near stall condition (NS). Through this study, it is supposed to have a deep understanding of the influence of stator hub clearance on the 3D corner separations and on the compressor performance.

\section{Experiment Setup}

The experiment is conducted on a low-speed large-scale axial compressor (LSLSAC) test facility at Beihang University, which is composed of a single-stage axial compressor with inlet guide vanes (IGV), as shown in Figure 1. The casing diameter was $1 \mathrm{~m}$, and the hub-to-tip ratio was 0.6. The rotor and stator blades were nearly radially stacked by controlled diffusion airfoil (CDA). The rotor was rotated at 1100 RPM, while the stator hub was stationary. At the design condition, the load coefficient based on the rotor speed at the middle span was approximately 0.5 , and the diffusion factor was about 0.5 for both the rotor and the stator at the middle span. The nominal rotor tip clearance was kept to be $1 \%$ blade height, while the nominal stator hub clearance is varied at $0.0 \%, 0.25 \%, 0.5 \%$, and $1.0 \%$ blade height, which will be denoted as $0.00 \tau, 0.25 \tau, 0.50 \tau$ and $1.00 \tau$, respectively. More detailed design parameters are summarized in Table 1, which were also introduced in [28-30]. 
In order to measure the performance of the compressor, static pressure taps are set at varies axial locations on the casing wall, as shown in Figure 2. At plane 0, four circumferential static pressure taps were used to measure the mass flow coefficient. The static pressure rise of the compressor was measured by four circumferential static pressure taps at plane 1 and six circumferential static pressure taps at plane 5. The inlet total pressure was the ambient pressure, which was measured by an atmospheric pressure gauge. The outlet total pressure was measured by the pitot probes at plane 5 . A torque meter was used to measure the input shaft power to the compressor, and combining with the inlet and outlet total pressure, the compressor efficiency can be calculated consequently.

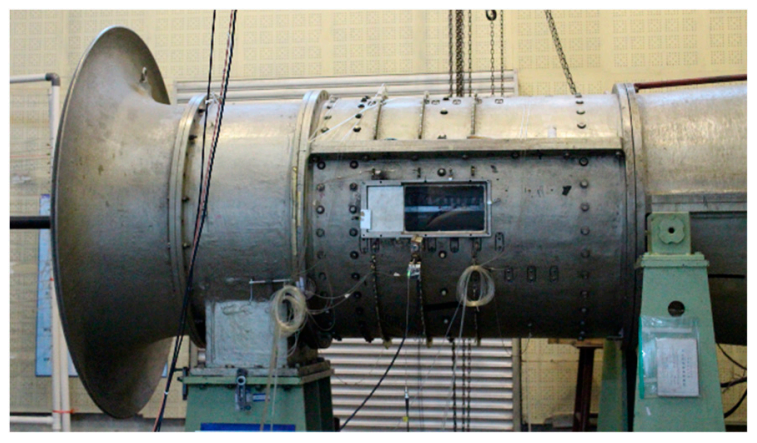

Figure 1. Low-speed large-scale axial compressor (LSLSAC) test facility.

Table 1. Design parameters of the compressor test facility.

\begin{tabular}{cc}
\hline Outer diameter $(\mathrm{mm})$ & 1000 \\
Hub-to-tip ratio & 0.6 \\
Number of blades & $36(\mathrm{IGV}) ; 17$ (rotor); 20 (stator) \\
Blade camber angle $\left(^{\circ}\right)$ & $7(\mathrm{IGV}) ; 34.3$ (rotor); 45.3 (stator) \\
Blade stagger angle $\left(^{\circ}\right)$ & $5(\mathrm{IGV}) ; 37.7$ (rotor); 18.1 (stator) \\
Blade nominal height $(\mathrm{mm})$ & $200(\mathrm{IGV}) ; 200$ (rotor); 200 (stator) \\
Blade chord $(\mathrm{mm})$ & $95(\mathrm{IGV}) ; 172$ (rotor); 183 (stator) \\
Rotor tip nominal clearance $(\mathrm{mm})$ & 2.0 \\
Stator tip nominal clearance $(\mathrm{mm})$ & $0.0 / 0.5 / 1.0 / 2.0$ \\
\hline
\end{tabular}

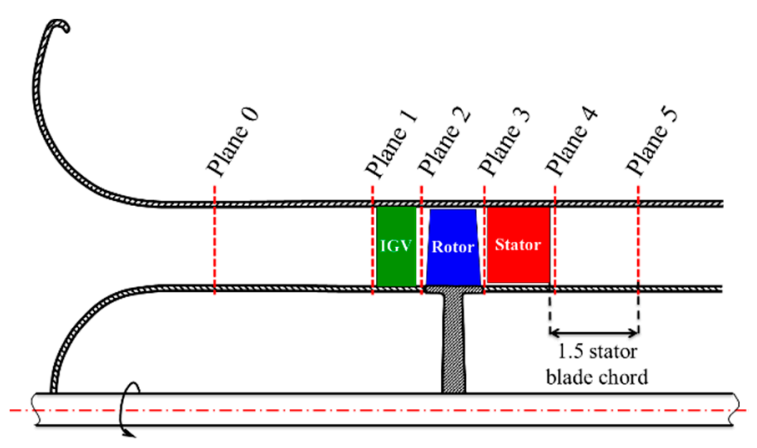

Figure 2. Schematics of the measurement locations on LSLSAC.

An L-shaped five-hole probe was used to measure the 3D velocity and pressure profiles at the inlet and outlet of the stator, i.e., at planes 3 and 4 . At the radial direction, the nearest measured position to the shroud and the hub wall was $2.5 \%$ and $2 \%$ blade height, respectively. The detailed arrangement of the five-hole probe's measurement points is shown in [31]. In order to measure the 3D flow field of the stator outlet when the open corner separation occurs, the measured pressure was processed with a zone method like the one used for the seven-hole probe [32], and the measurable flow angle range was extended to $60^{\circ}$. The pressure was acquired by the Rosemount 3051S1 differential pressure transducers, the measuring range, and uncertainty of which were $\pm 6.22 \mathrm{KPa}$ and $0.025 \% \mathrm{FS}$. After detailed analysis, the measurement uncertainties of five-hole probe were $0.5^{\circ}$ for the flow angles, $1 \%$ (normalized by the 
flow dynamic pressure) for the total pressure, $2 \%$ (normalized by the flow dynamic pressure) for the static pressure, and $1 \%$ for the flow velocity, respectively.

Oil-flow visualization tests are conducted on the suction surface and end wall of the stator passage, to reveal the evolution of the flow pattern at various flow coefficient when stator hub clearance size is changed. Detailed introduction of the oil-flow visualization can be found in [28]. In the present study, the investigated flow conditions by the oil-flow visualization and five-hole probe are shown in Table 2, where $\varphi$ is the mass flow coefficient.

Table 2. The investigated flow conditions by the oil-flow visualization and five-hole probe.

\begin{tabular}{|c|c|c|c|c|c|c|}
\hline Clearance & Conditions & $\operatorname{DE}(\varphi=0.6)$ & $\mathrm{PP}(\varphi=0.55)$ & $\mathrm{P} 1(\varphi=0.525)$ & $\mathrm{P} 2(\varphi=0.5)$ & NS $(\varphi=0.48)$ \\
\hline & $0.00 \tau$ & $5 \mathrm{~h}$ and $\mathrm{Oil}^{1}$ & $5 \mathrm{~h}$ and Oil & Oil & Oil & $5 \mathrm{~h}$ and Oil \\
\hline & $0.25 \tau$ & $5 \mathrm{~h}$ and Oil & $5 \mathrm{~h}$ and Oil & - & - & $5 \mathrm{~h}$ and Oil \\
\hline & $0.50 \tau$ & $5 \mathrm{~h}$ and Oil & $5 \mathrm{~h}$ and Oil & - & - & $5 \mathrm{~h}$ and Oil \\
\hline & $1.00 \tau$ & $5 \mathrm{~h}$ and Oil & $5 \mathrm{~h}$ and Oil & - & - & $5 \mathrm{~h}$ and Oil \\
\hline
\end{tabular}

1 " $5 \mathrm{~h}$ " represents five-hole probe measurement, “Oil” represents oil-flow visualization test.

\section{Results}

\subsection{Overall Characteristics of the Compressor}

The overall characteristics of the tested compressor with different stator hub clearances are shown in Figure 3, where the stage static pressure rise coefficient $C_{p s}$ and the torque efficiency are expressed as functions of the mass flow coefficient $\varphi$. As can be seen, for the static pressure rise coefficient $C_{p s}$, when a small stator hub clearance $(0.25 \tau)$ was introduced the value at large mass flow rate conditions ( $\varphi>0.54)$ almost did not change, but at small mass flow rate conditions $(\varphi<0.54)$ it increased to some extent; as the stator hub clearance increased to $0.50 \tau$, the value at large mass flow rate conditions ( $\varphi>0.57)$ changed little, and at small mass flow rate conditions $(\varphi<0.57)$ it increased continually. When the stator hub clearance increased to $1.00 \tau$, however, the value at all conditions decreased but it was still higher than that of $0.00 \tau$ and $0.25 \tau$ at small mass flow rate conditions $(\varphi<0.54)$. For the torque efficiency, when stator hub clearance was introduced the value at large mass flow rate conditions decreased and at small mass flow rate conditions increased, for all three clearance cases; like the static pressure rise coefficient $C_{p s}$, at large mass flow rate conditions the value of the torque efficiency changed little from $0.25 \tau$ to $0.50 \tau$, and decreased slightly from $0.50 \tau$ to $1.00 \tau$; at small mass flow rate conditions, the value of the torque efficiency increased enormously from $0.25 \tau$ to $0.50 \tau$, but decreased a little from $0.50 \tau$ to $1.00 \tau$.

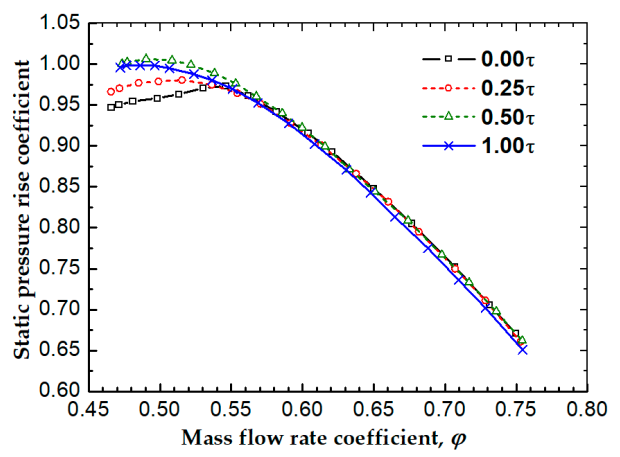

(a) stage static pressure rise coefficient

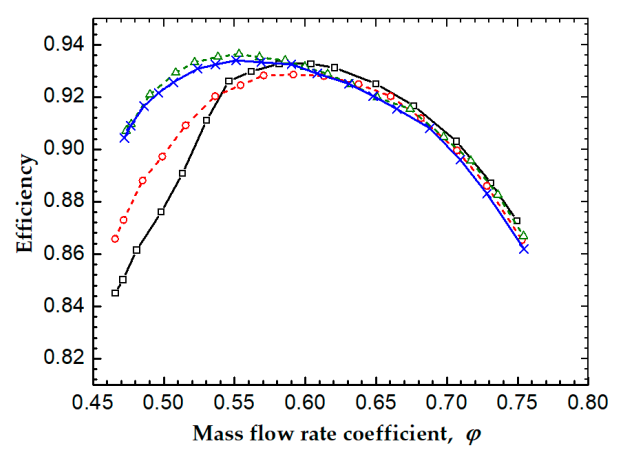

(b) stage torque efficiency

Figure 3. Characteristics of the tested compressor.

From above, when stator hub clearances were introduced, there existed an optimum stator hub clearance that made the compressor performance optimal, and this optimum stator hub clearance 
should between $0.50 \tau$ and $1.00 \tau$ (much closer to $0.50 \tau$ ). In addition, it can be seen that at $0.00 \tau$, both the operating line of the stage static pressure rise coefficient $C_{p s}$ and the torque efficiency turn abruptly around $\varphi=0.54$, but this phenomenon disappears as long as the stator hub clearance is introduced, i.e., the operating line becomes smoother near $\varphi=0.54$.

\subsection{The Evolution of Stator Corner Separation at Zero Clearance}

At zero clearance, the oil-flow visualization results at five mass flow coefficient, i.e., $\mathrm{DE}(\varphi=0.6)$, PP $(\varphi=0.55)$, P1 $(\varphi=0.525)$, P2 $(\varphi=0.5)$, NS $(\varphi=0.48)$, are shown in Figure 4. As there are no obvious separation topologies on the shroud and the blade pressure side, only results on the suction side and the hub are shown here.

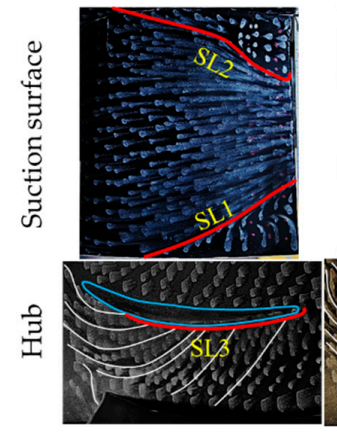

(a) DE

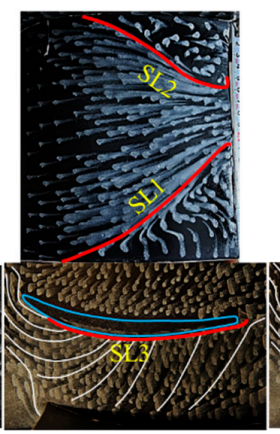

(b) PP

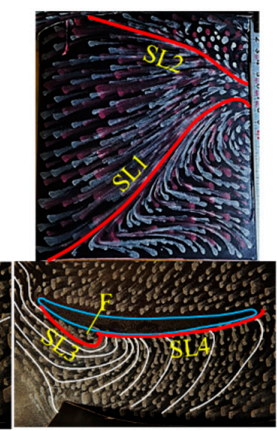

(c) P1

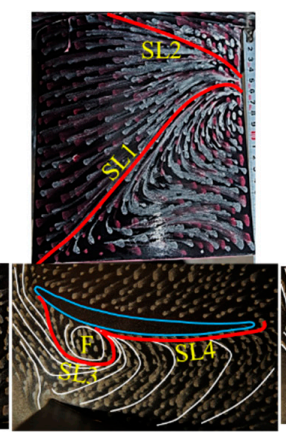

(d) P2

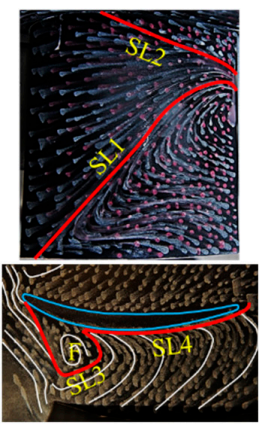

(e) NS

Figure 4. The development of the stator corner separation when the hub clearance was sealed.

It can be seen that both the hub corner separation (HCS) and the tip corner separation (TCS) exist at all conditions. For the hub corner separation (SL1 in Figure 4), the spanwise scale of the separation increased continually with the decline of the mass flow, while for the tip corner separation (SL2 in Figure 4) the spanwise scale of the separation changed little at first then dropped slightly as the mass flow decreased. Figure 5 shows the variation of the spanwise scale of the separation along with the mass flow rate coefficient. It can be seen that for the hub corner separation there was a sudden increase between PP and P1, before and after where the spanwise scale of the hub separation increases slowly. From the oil-flow visualization results, it can be seen that just starting from P1 a focus point $\mathrm{F}$ appears on the hub, and the backflow also occurs, which means the hub corner separation has turned into corner stall. This result coincides well with the phenomenon observed in another axial compressor stator investigated by the authors [28], i.e., hub corner stall usually happens suddenly as the mass flow decreases.

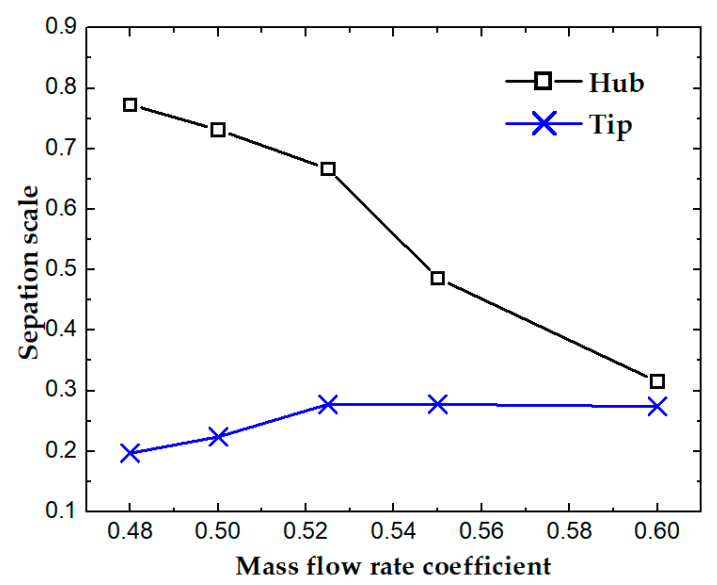

Figure 5. Variation of the separation scales when the hub clearance was sealed. 


\subsection{Influence of the Size of Stator Hub Clearance on the Evolution of Flow Topologies}

To investigate the effect of stator hub clearance on the 3D separating flows inside the stator passage, oil-flow visualization tests were conducted at three mass flow conditions including $\mathrm{DE}(\varphi=0.6)$, $\operatorname{PP}(\varphi=0.55)$, and NS ( $\varphi=0.48)$. In addition, to quantitatively analyze the flow pattern in the stator, a five-hole probe is also used to measure the $3 \mathrm{D}$ flow velocity, flow angles, and pressure at the stator inlet and outlet, also at the above three conditions.

\subsubsection{Results at the DE Condition}

The oil-flow visualization results in the DE condition are shown in Figure 6. Similarly, only results on the suction side and the hub are shown here. Compared with the results at zero clearance, the scale of the tip corner separation almost did not change with the introduction of the stator hub clearances. For the hub corner separation, the situation is different as the stator hub clearance varies. Firstly, when the clearance was small $(0.25 \tau)$, the spanwise scale of the hub corner separation expanded to some extent and the hub corner separation originated earlier than that at zero clearance, which was also visualized by Gbadebo, et al. [22]. In addition, the separation line on the hub, SL3, was replaced by three separation lines, i.e., SL3, SL4, and SL5. It should be noted that SL4 points to the upstream, which is contrary to the direction of SL4 and SL5, and between SL3 and SL4 there exists a focus point, F, while between SL4 and SL5 there exists a saddle point, S. Then, when the stator hub clearance grows to $0.50 \tau$, the separation line SL1 on the blade suction surface disappears and is replaced by an attachment line AL2, besides, the separation lines on the hub becomes one separation again (the SL3 in Figure 6c) and it was significantly far away from the blade suction side. Finally, when the stator hub clearance increases to $1.00 \tau$, the flow structure was similar to that at $0.50 \tau$, but the separation line SL3 on the hub is further away from the blade suction surface.

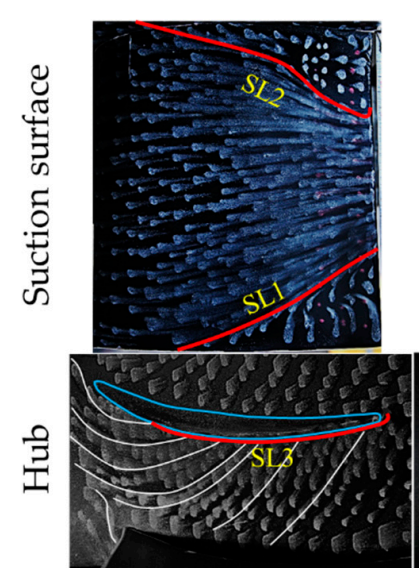

(a) $0.00 \tau$
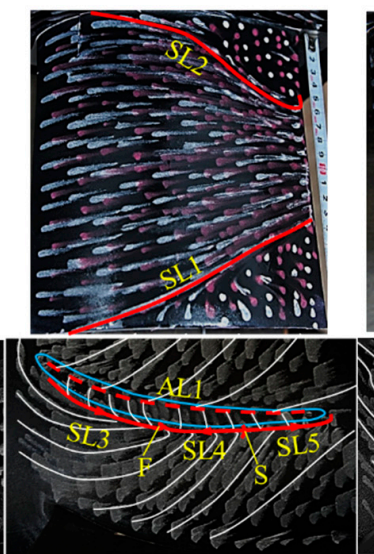

(b) $0.25 \tau$

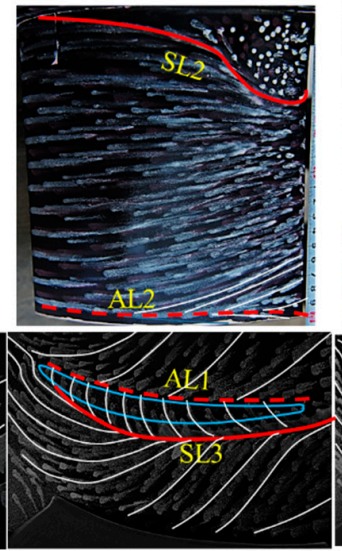

(c) $0.50 \tau$

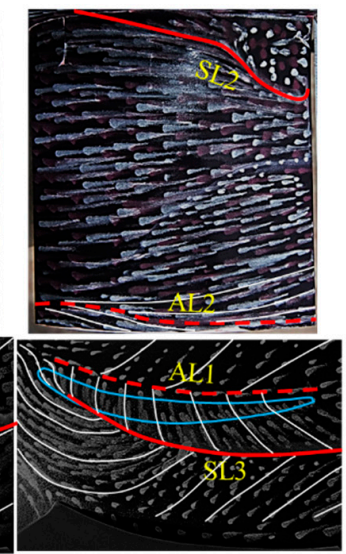

(d) $1.00 \tau$

Figure 6. The evolution of flow topologies on the suction surface and hub with the variation of hub clearance at the design condition (DE) condition.

The flow structures on the hub corner of a cantilevered stator depends on the interaction of the secondary flow and the clearance leakage flow. When the stator hub clearance changed, the secondary flow was effected slightly, but clearance leakage flow was effected obviously, for example, Rains [33] pointed out that when the flow leaks from the blade pressure side to the blade suction side, the flow property inside the clearance mainly depends on the nondimensional clearance size, $\lambda^{2} \operatorname{Re} \epsilon$ (where $\lambda$ is the ratio of the clearance size to the maximum thickness of the blade airfoil, $R e$ is the Reynolds number based on the blade chord and the mainflow velocity near the hub, $\epsilon$ is the ratio of blade maximum thickness to the blade chord), i.e., when $\lambda^{2}$ Ree $<21$, the flow inside the clearance was dominated by the flow viscosity, while when $\lambda^{2} \operatorname{Re} \epsilon>125$, the flow viscosity could be ignored. When the stator hub clearance equals to $0.25 \tau, \lambda^{2} \operatorname{Re\epsilon }=25$, the flow inside the clearance was mainly dominated by the 
flow viscosity, hence, large flow loss were generated when the flow leaks from the blade pressure side to the blade suction side, and the velocity of the clearance flow at the clearance outlet (the blade suction side) became very small. On the one hand, the very small transversal velocity component could not push away the secondary flow near the hub, so the separation line SL3 was very close to the blade suction side; on the other hand, when the streamwise adverse pressure along the blade suction side was very large, the very small streamwise velocity component separated and flowed backward, so the separation line SL4 pointed to the upstream, but when the streamwise adverse pressure along the blade suction side became small (at the rear part near the blade trailing edge) the clearance flow pointed to the downstream again, as shown as the separation line SL5. In this case, as there exists some backflow (between the focus point, F, and the saddle point, $\mathrm{S}$ ), the corner separation becomes even larger than that at $0.0 \tau$. When the stator hub clearance grows to $0.50 \tau$, the corresponding $\lambda^{2}$ Ree equals to 100 , where the flow viscosity cloud be nearly ignored, as a result, the clearance flow at the clearance outlet was strong enough to push away the secondary flow and resist the streamwise adverse pressure gradient, so the backflow, even together with the corner separation, disappeared.

The distributions of the normalized axial velocity at the stator outlet are shown in Figure 7. It can be seen that there was almost no difference in the tip corner separation induced flow blockage between different stator hub clearance cases. But for the hub corner separation induced flow blockage, when a small stator hub clearance $(0.25 \tau)$ was introduced, the shape of the blockage area changed little while the blockage area was enlarged and the velocity inside the blockage area becomes smaller; when the stator hub clearance grows to $0.50 \tau$, the spanwise scale of the blockage area becomes much smaller but the pitchwise scale became larger; the situation at $1.00 \tau$ was similar to that at $0.50 \tau$.

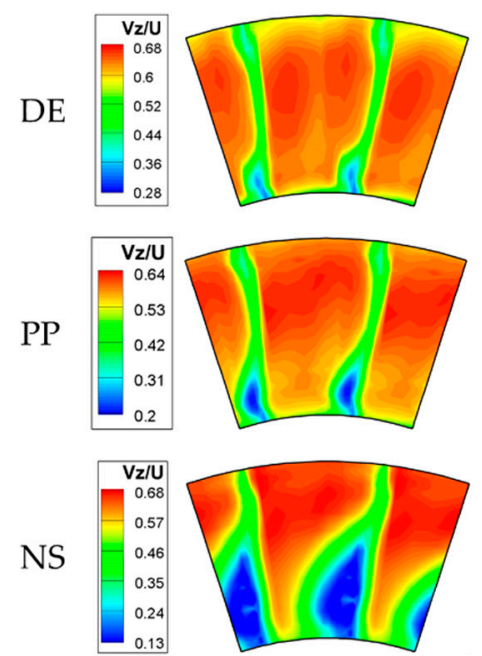

(a) $0.00 \tau$
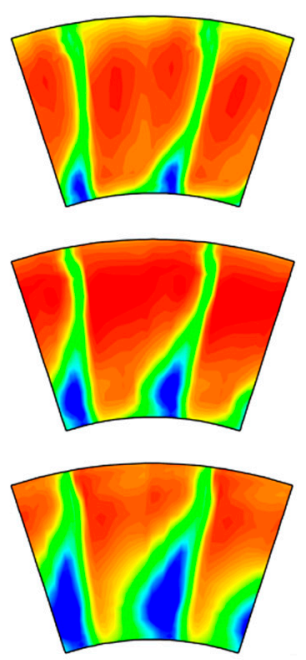

(b) $0.25 \tau$
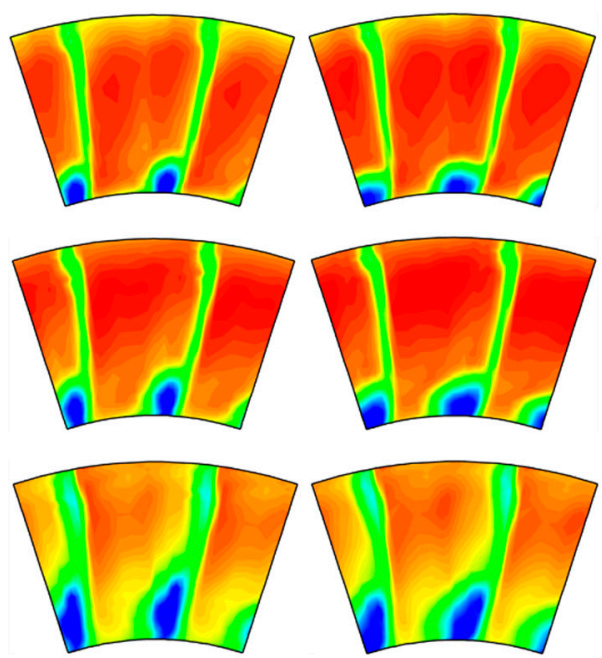

(c) $0.50 \tau$

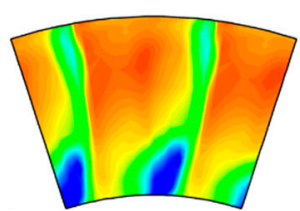

(d) $1.00 \tau$

Figure 7. Distribution of the normalized axial velocity at the stator outlet.

Combined with the oil-flow visualization results and the five-hole probe results, it can be seen that at zero clearance the flow structures at the hub corner were predominated by the corner separation. When a small stator hub clearance $(0.25 \tau)$ was introduced, though some hub leakage flow was brought about (see the separation line SL4 in Figure 6f), it was too weak to suppress the migration of the boundary layer low energy flows from the blade pressure side to the suction side, on the contrary, the very small streamwise velocity component separated and flowed backward under the large streamwise adverse pressure along the blade suction side, which led to an even stronger hub corner separation compared with that at zero clearance. Hence, the hub corner was predominated by both the corner separation and the tip leakage flow. When the stator hub clearance grew to $0.50 \tau$, the hub leakage flow was strong enough to restrain the secondary flows on the hub, hence, the separation line SL1 on the blade suction side disappeared and an attachment line AL2 on the blade suction side arose 
and the separation line SL3 on the hub left far away from the hub corner, so in this case the hub corner was predominated by the hub leakage flow and that is why the hub corner blockage area at the stator outlet becomes smaller in the spanwise direction and larger in the pitchwise direction; when the stator hub clearance increases to $1.00 \tau$, the hub leakage flow becomes stronger and the hub corner is still predominated by the hub leakage flow.

\subsubsection{Results at the PP Condition}

The oil-flow visualization results in the PP condition are shown in Figure 8. It can be seen that at this condition the tip corner separation did not change with the variation of the stator hub clearances either. For the hub corner, the influence of hub clearance was mostly like the situation at the DE condition but with a little difference. When a small stator hub clearance $(0.25 \tau)$ was introduced, the scale of the separation on the blade suction surface increases, and at the end of the separation line SL3 a focus point, F, appears, but after the focus point only one separation line (SL4) formed and it pointed to the upstream, which means that the flow separation originated from the separation line, SL3 did not reattach at the rear part of the blade suction surface like the situation at the DE condition, i.e., at this condition the closed separation turns into the open separation (hub corner stall). When the stator hub clearance increased to $0.50 \tau$, the separation lines on the hub became one separation again and an attachment line AL2 comes out on the blade suction surface, but the separation line SL1 on the blade suction surface does not vanish like that at the DE condition and is pushed to the blade rear part near the blade trailing edge and with a very small scale. When the stator hub clearance continually increased to $1.00 \tau$, the separation line SL1 on the blade suction surface thoroughly disappeared, and the separation line SL4 on the hub was located further away from the blade suction side.

Combined with the five-hole probe results in Figure 7, it could be concluded that at the PP condition, the hub corner at zero clearance is still predominated by the corner separation; the introduction of a small stator hub clearance $(0.25 \tau)$ prompts the occurrence of the hub corner stall, so at $0.25 \tau$ the hub corner was predominated by the hub leakage flow and the corner stall; when the stator hub clearance equalled to $0.50 \tau$, the hub corner separation was mostly suppressed by the leakage flow, and only little low energy flow in the end wall boundary climbed on the blade suction surface near the trailing edge, hence, at $0.50 \tau$ the stator hub corner is predominated by both the corner separation and the tip leakage flow; when the stator hub clearance increased to $1.00 \tau$, the hub leakage flow became strong enough to thoroughly suppress the migration of the end wall boundary layer, so the hub corner was completely predominated by the hub leakage flow.

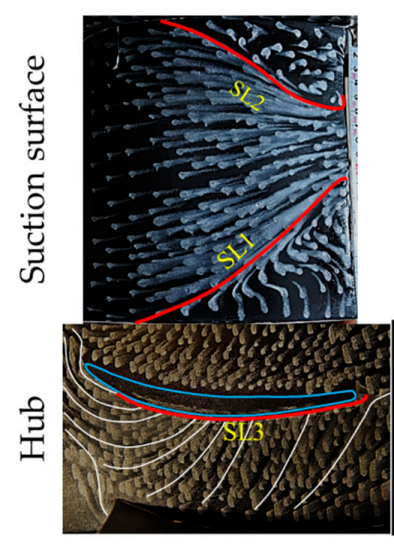

(a) $0.00 \tau$

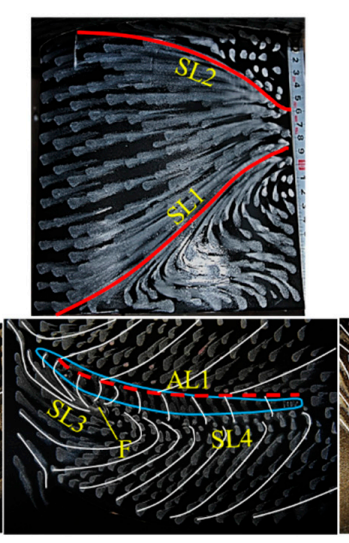

(b) $0.25 \tau$

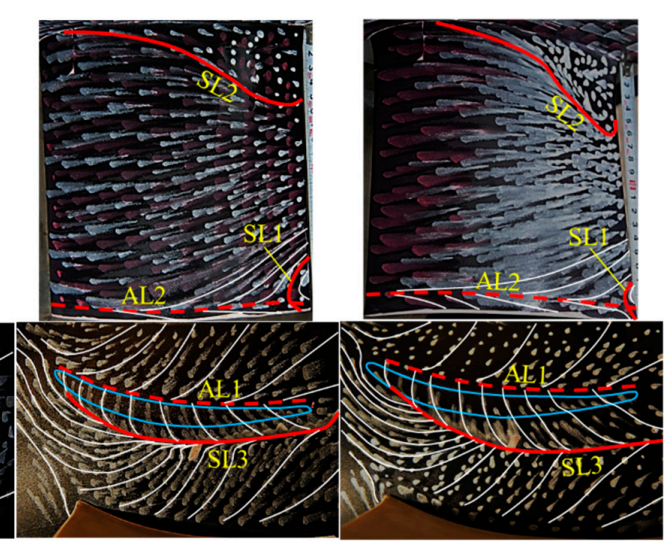

(c) $0.50 \tau$

(d) $1.00 \tau$

Figure 8. The evolution of flow topologies on the suction surface and hub with the variation of hub clearance at the peak static pressure rise condition (PP) condition. 


\subsubsection{Results at the NS Condition}

The oil-flow visualization results at the NS condition are shown in Figure 9. As mentioned above, the hub corner stall occurs at zero clearance. When a small stator hub clearance $(0.25 \tau)$ is introduced, the tip corner separation almost does not change; as to the hub corner, the flow structure does change significantly either, i.e., the corner stall still exists, but with a smaller pitchwise scale (also can be seen from Figure 7). It should be noted that at this condition the introduction of a small stator hub clearance is beneficial to improve the flow, which is contrary to the situation at DE and PP condition. Actually, the absolute different influence of the hub leakage flow is associated with the flow structure in the hub corner, i.e., when the hub corner stall occurred at NS condition, the secondary flow had large velocity component that points to the upstream, which led to the massive low energy flow in the end wall boundary being transported into the recirculation region around focus point $\mathrm{F}$; when a small clearance $(0.25 \tau)$ was introduced, even though the leakage flow had low streamwise velocity component, it can still reduce the transport effect of the secondary flow, hence, the pitchwise scale of the hub corner stall decreased. When the stator hub clearance increased to $0.50 \tau$, the hub leakage flow was strong enough to push the secondary flow away from the suction/hub corner and significantly prevent the secondary flow transporting the end wall boundary flow into the recirculation region around focus point $\mathrm{F}$, as a result, the recirculation region was much decreased and the hub corner stall disappeared, but as the leakage flow was not strong enough to push away all the secondary flow, hub corner separation still existed at the rear part, just like the flow structure of $0.25 \tau$ at DE condition and $0.5 \tau$ at PP condition. When the stator hub clearance increased to $1.00 \tau$, the flow topologies were similar to that at $0.50 \tau$, but the spanwise scale of SL1 decreases and the spanwise scale of SL2 increased and SL4 was located further away from the blade suction side.

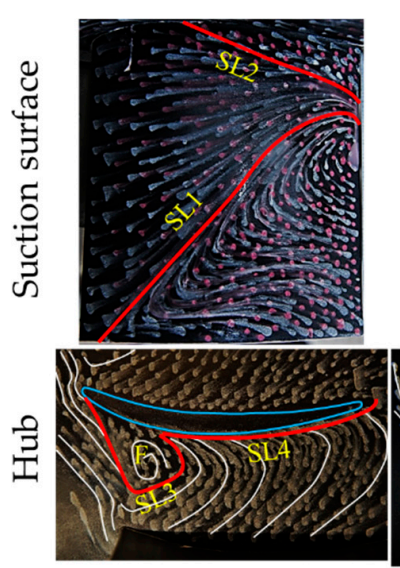

(a) $0.00 \tau$

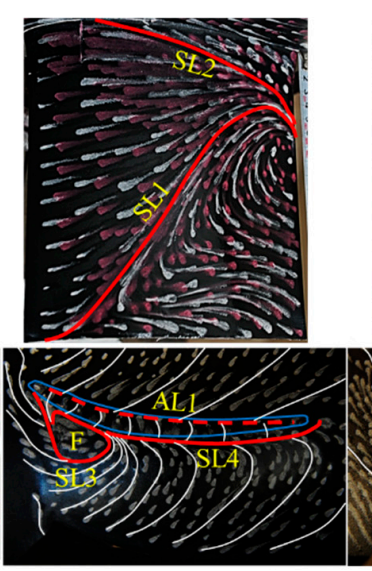

(b) $0.25 \tau$

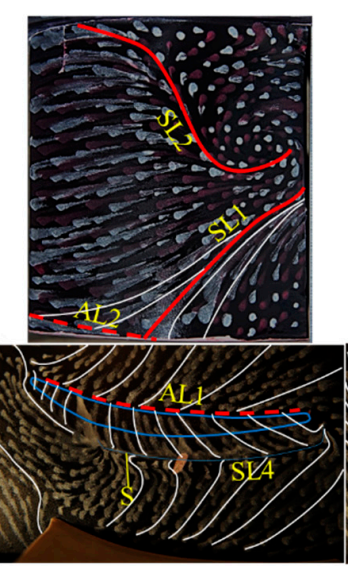

(c) $0.50 \tau$

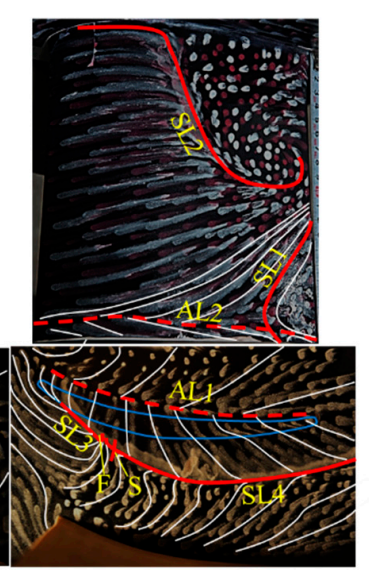

(d) $1.00 \tau$

Figure 9. The evolution of flow topologies on the suction surface and hub with the variation of hub clearance at the near stall condition (NS) condition.

Combined with the five-hole probe results in Figure 7, it could be concluded that at zero clearance and $0.25 \tau$, the hub corner is predominated by both the corner stall and hub leakage flow, and when stator hub clearance increases to $0.50 \tau$ and $1.00 \tau$, instead, the hub corner is predominated by both the corner separation and the hub leakage flow.

\subsection{Typical Flow Structures in the Stator Hub Corner}

From above, there were five typical flow structures in the stator hub corner as the stator hub clearance varies, as shown in Figures 10 and 11. The first one, named Type A, features as the traditional hub corner separation, which mainly existed at large mass flow rate conditions with zero stator hub clearance. When the stator hub corner was predominated by Type A, the induced flow blockage at the 
stator outlet was very small. The second one, named Type B, features as the traditional hub corner stall, which mainly exists at small mass flow rate conditions with zero stator hub clearance. When the stator hub corner is predominated by Type B, the induced flow blockage at the stator outlet is relatively large. No matter for Type A or Type B, the hub corner flow blockage region at the stator outlet was more like a triangle, i.e., the transition from the hub corner to the blade wake is relatively smooth. The third one, named Type $C$, features as the leakage flow, which mainly exists at large mass flow rate conditions with large stator hub clearances. When the stator hub corner was predominated by Type $C$, the induced flow blockage region at the stator outlet is relatively small and the shape of the blockage region is more like an ellipse, of which the long axis was along the pitchwise direction and the short axis was along the spanwise direction, besides, the transition from the hub corner to the blade wake was abrupt. The fourth one, named Type D, features as the coexistence of the leakage flow and the hub corner separation, which mainly exists at small mass flow rate conditions with large stator hub clearances or large mass flow rate conditions with very small stator hub clearances. When the stator hub corner was predominated by Type $\mathrm{D}$, the induced flow blockage region at the stator outlet was between the one of Type A and Type B, no matter in the scale or the shape. The last one, named Type E, features as the coexistence of the leakage flow and the hub corner stall, which mainly exists at small mass flow rate conditions with small stator hub clearances. When the stator hub corner was predominated by Type E, the induced flow blockage region at the stator outlet was much like the one of Type B.

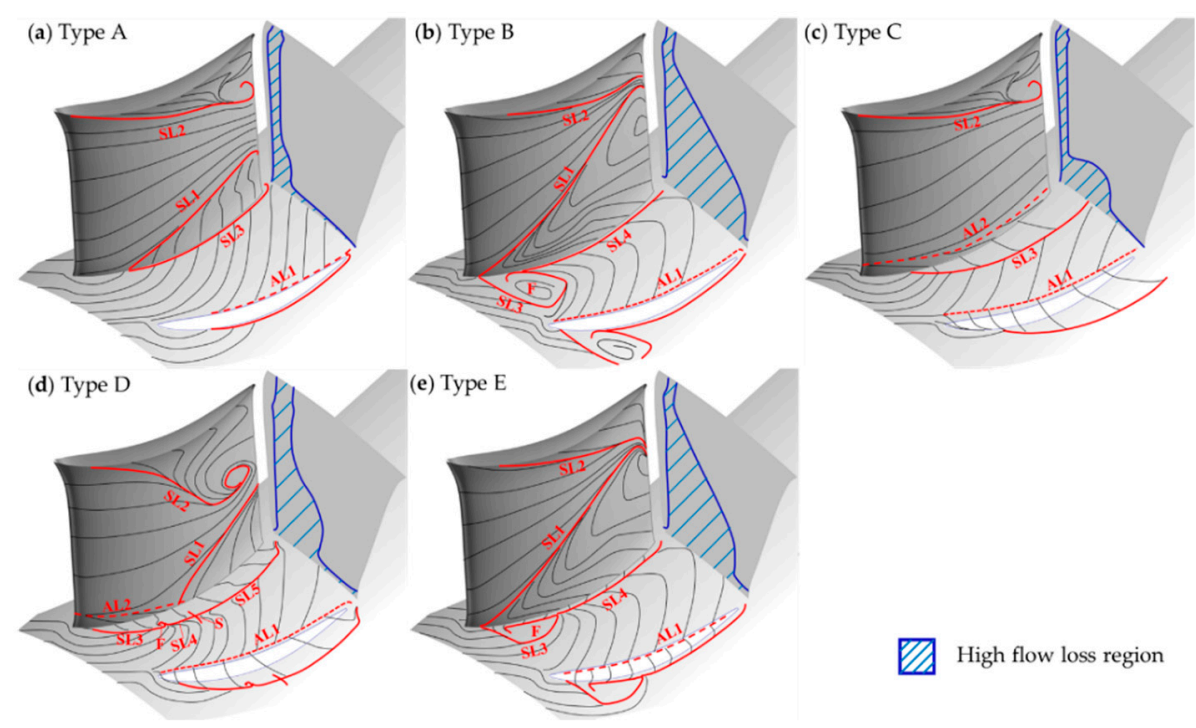

Figure 10. Typical flow topologies inside the stator passage.

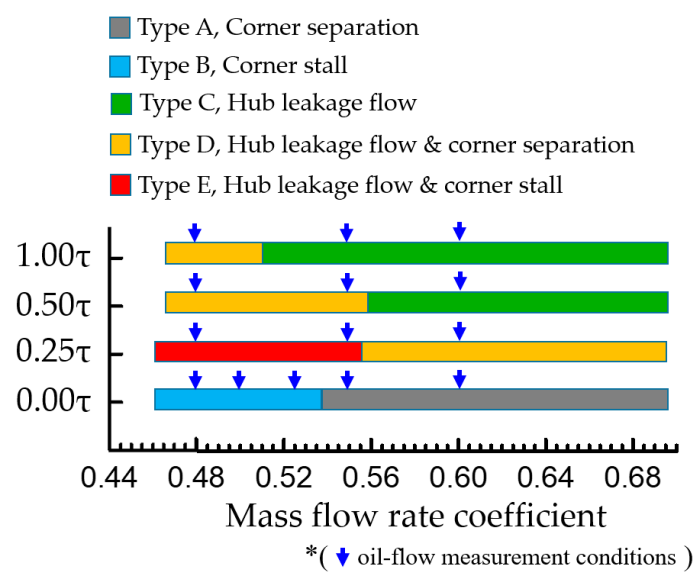

Figure 11. Secondary flows that dominate the stator hub corner. 
From Figure 11 it can be seen that when the stator hub clearance was big enough, the corner stall did not occur in the whole compressor operating range, and from the rear analysis it can be seen that the stator incidence almost does not change with the variation of the stator hub clearance, which means that the critical incidence phenomenon was not applicable again when stator hub clearance exists (when the stator hub clearance is not very small). Actually, corner separations usually originate from the migrant of the low energy boundary layer flow in the end wall under the transverse pressure gradient from the blade pressure side to the blade suction side, then with the effect of the streamwise adverse pressure gradient, the streamline turned to the upstream direction. With the increment of the blade loading, the streamwise adverse pressure gradient increases, and the streamline curvature becomes severer and severer, until the streamline turns $180^{\circ}$, the corner stall will occur without warning and large flow blockage and loss will be introduced [2]. When stator hub clearances (not too small) exist, on the one hand, the introduced leakage flow has opposite flow direction to the transverse secondary flow near the hub, which can blow away the low energy flow that accumulated at the suction/hub corner; on the other hand, the hub corner is surrounded by the leakage flow and the main flow, both of which have relatively high streamwise velocity, so the transportation of the secondary low energy flow that rolls into the recirculation region around focus point $\mathrm{F}$ was suppressed; as a result, the hub corner stall was eliminated or delayed. In addition, it is worth noting that the flow structure at the corner is a result of the contest between the leakage flow and the secondary flow, i.e., when the leakage flow is just strong enough to eliminate the corner stall, the corner separation still exists and the corner is predominated by both the leakage flow and the corner separation; in this case, if the leakage flow increases, corner separation may vanish, but the enhanced leakage flow will bring about more loss. Hence, it seems that an opportune coexistence of the leakage flow and the corner separation can yield the highest performance.

Another problem that should be paid attention to is the situation when the stator hub clearance is very small, i.e., $0.25 \tau$ in this paper. The introduction of this small stator hub clearance will prompt the occurrence of the hub corner stall. But in this case, the occurrence of the hub corner at the PP condition does not induce an abrupt increase of the flow blockage or loss, and as the mass flow rate decreases the development speed of the hub corner stall is lower than that at zero clearance (at the NS condition, though the spanwise scale of the hub corner stall of $0.25 \tau$ is comparable, the pitchwise scale is much smaller than that at zero clearance, as shown in Figure 7). This is why at $0.25 \tau$ there was no saltation on the compressor operating line around $\varphi=0.54$. When the stator hub clearance increases to $0.50 \tau$ or $1.00 \tau$, no hub corner stall exists, so there is no saltation on the compressor operating line around $\varphi=0.54$ either.

\section{Discussion}

As mentioned above, the evolution of the flow topologies inside the stator passage along with the variation of stator hub clearance is complicated, and this has an obvious influence on the performance of the compressor. Hence, in this section, the flow mechanisms of the effect of the stator hub clearance on the compressor performance will be discussed.

\subsection{Source of the Variation of the Compressor Performance}

As mentioned above, when stator hub clearances are introduced, the overall characteristics of the compressor changes obviously, especially at small mass flow rate conditions. To clearly analyze the flow mechanisms, the static pressure rise coefficients of the compressor stage, the rotor, and the stator at three typical mass flow rate conditions are shown in Figure 12. Here, all the pressure rise coefficients are calculated by the corresponding pressure rise dividing by $1 / 2 \rho U_{m}{ }^{2}\left(U_{m}\right.$ is the rotor speed at middle span), and the stage static pressure rise is calculated by the compressor inlet static pressure and the pressure measured by the five-hole probe at Plane 4 (as shown in Figure 2); the rotor static pressure rise is calculated by the compressor inlet static pressure and the pressure measured by 
the five-hole probe at Plane 3 (as shown in Figure 2); and the stator static pressure rise is calculated by the pressure at Plane 3 and the pressure at Plane 4.

For the stage static pressure rise coefficient, it can be seen that the distribution shown here is similar to the results in Figure 3, but with a smaller value at all conditions. This is mainly due to the difference in the data-acquired location of the static pressure rise coefficient, i.e., the results shown in Figure 3 are calculated by the compressor inlet static pressure and the pressure at plane 5 (as shown in Figure 2) which is far away from plane 4 . From plane 4 to plane 5, the blade wake and the corner separating flow mix with the main flow, which results in a static pressure rise to some extent. For the stator static pressure rise coefficient, the variation of the value along with the stator hub clearance is very small at the $\mathrm{DE}$ condition, then becomes bigger at the PP condition, and finally becomes extremely large at the NS condition. For the rotor static pressure rise coefficient, the variation of the value along with the stator hub clearance is very small at the DE and the PP condition and then becomes a little obvious at the NS condition. Besides, at the NS condition the tendency of the variation of the rotor static pressure rise coefficient along with the stator hub clearance is almost opposite to that of the variation of the stator static pressure rise coefficient, but the amplitude of the variation of the rotor static pressure rise coefficient is much smaller than that of the stator static pressure rise coefficient. Hence, as a result, at all conditions the tendency of the variation of the stage static pressure rise coefficient along with the stator hub clearance is the same as that of the stator static pressure rise coefficient, which means that the variation of the compressor static pressure rise when stator hub clearance changes is mainly due to the variation of the flow inside the stator passage.

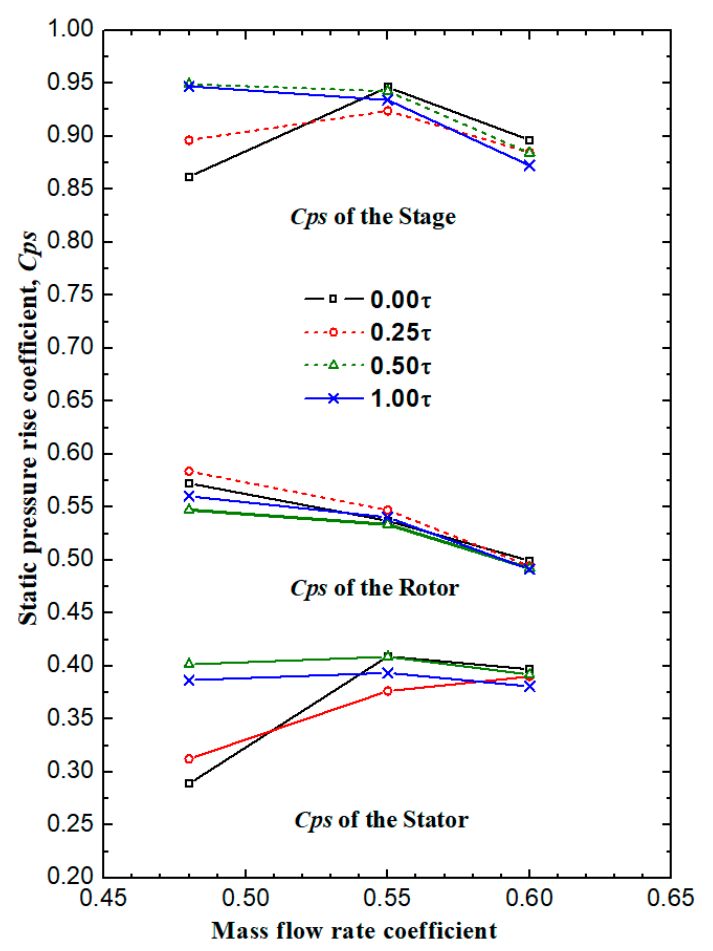

Figure 12. The static pressure rise coefficients of the compressor stage, the rotor, and the stator measured by using the five-hole probe.

From above, when the stator hub clearance varies, the rotor static pressure rise almost does not change, which means that the stator hub clearance has little effect on the operating condition of the rotor. The stator total pressure loss coefficient obtained from the five-hole probe results is shown in Figure 13. At the DE condition, the stator with no stator hub clearance has the lowest loss; when a small stator hub clearance $(0.25 \tau)$ is introduced, the loss increases to some extent; when the stator hub clearance increases to $0.50 \tau$, the stator loss drops slightly; and when the stator hub clearance 
continually increases to $1.00 \tau$, the stator loss grows up again; this coincides well with the tendency of the variation of the compressor efficiency along with the stator hub clearances (as shown in Figure 3). At the PP condition, the stator with a stator hub clearance $0.50 \tau$ gets the lowest loss, and the loss at the other three stator hub clearance cases is almost the same, which agrees well with the tendency of the variation of the compressor efficiency, too. At the NS condition, the variation of the stator loss when the stator hub clearance changes is much more significant than the other two conditions, and the stator with large stator hub clearances $(0.50 \tau$ and $1.00 \tau)$ can result in a much lower loss than with small stator hub clearances, and among these the stator with the $0.50 \tau$ stator hub clearance has the lowest loss and the stator with no stator hub clearance has the highest loss, which is also in accordance with the tendency of the variation of the compressor efficiency. Hence, it can be seen that the variation of the compressor efficiency when stator hub clearance changes is also mainly due to the variation of the flow inside the stator passage.

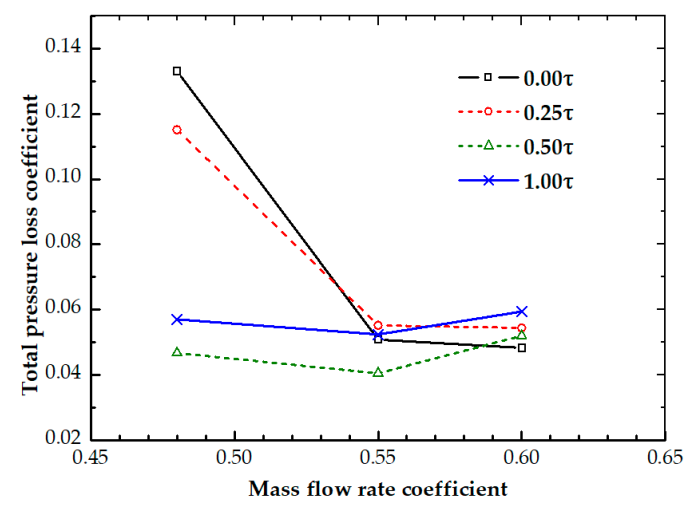

Figure 13. The stator total pressure loss coefficient obtained from the five-hole probe results.

\subsection{Effect of Stator Hub Clearances on the Stator Performance}

To have a clear understanding of the flow mechanisms of the effect of stator hub clearances on the stator performance, the flow profiles before and after the stator passage obtained using the five-hole probe will be discussed in this section. The circumferential averaged distribution of the total pressure and the incidence at the stator inlet are shown in Figure 14, where results at all stator hub clearances are displayed. It can be seen that the difference of the circumferential averaged parameters between different stator hub clearance cases is very small, which validates the conclusion drawn above. In addition, at the NS condition, the stator incidence near the hub is about $7^{\circ}$, which has already exceeded the critical incidence (about $5.2^{\circ}$, as revealed in [34], hence, the hub corner stall occurs at zero clearance.

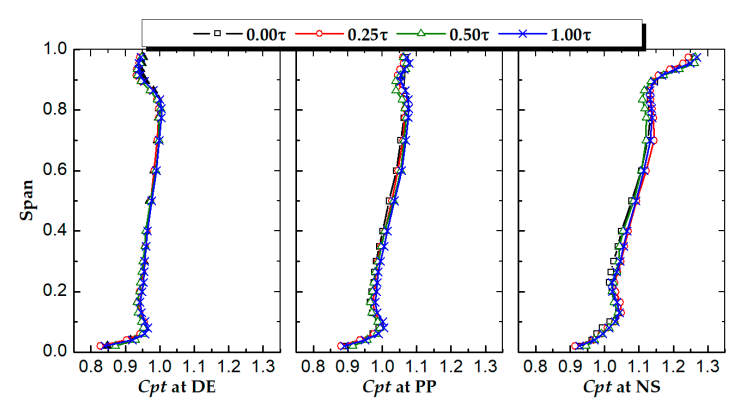

(a) total pressure coefficient

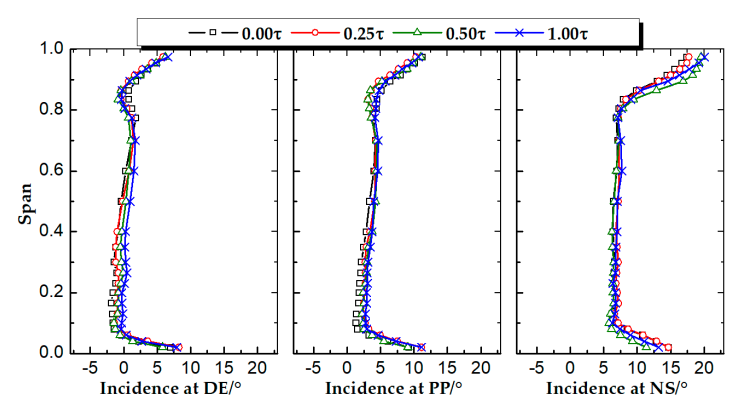

(b) incidence angle

Figure 14. Circumferentially averaged flow parameters at stator inlet.

The circumferential averaged distribution of the flow angle at the stator outlet is shown in Figure 15. It can be seen that at zero clearance the over-turning phenomenon near the hub is very 
serious, while it is much weaker near the tip. When a small stator hub clearance is introduced, a weak leakage flow is induced, as a result, the migrant of the low energy flow near the end wall is suppressed to some extent, so the overturning phenomenon near the hub is decreased slightly. When the stator hub clearance increases to $0.50 \tau$, the leakage flow becomes stronger and the suppression of the migrant of the low energy flow near the end wall is enhanced, so the overturning phenomenon is obviously decreased. When the stator hub clearance continually increases to $1.00 \tau$, the leakage flow becomes further stronger, which is more than enough to suppress the migrant of the low energy flow near the end wall, so the flow near the hub becomes a little of lack of turning. This coincides well with the oil-flow visualization results discussed above.

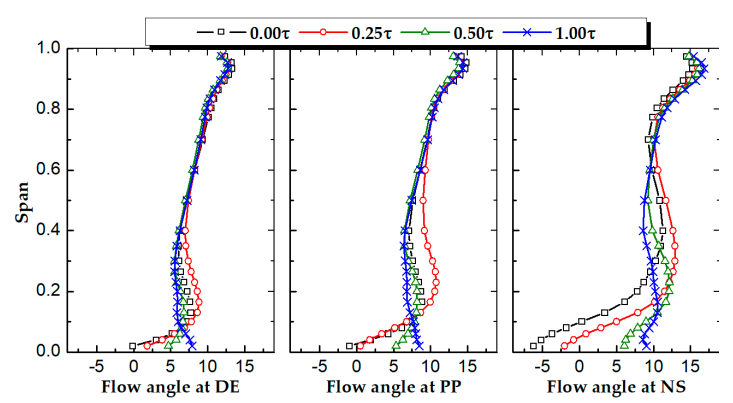

(a) flow angle

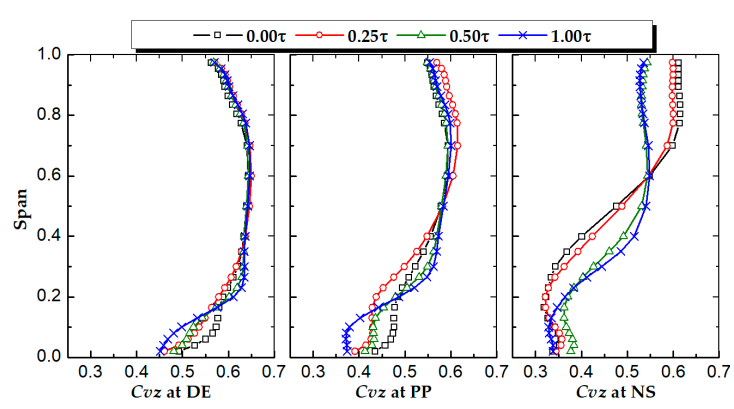

(b) normalized axial velocity

Figure 15. Circumferentially averaged flow parameters at the stator outlet.

The circumferential averaged distribution of the normalized axial velocity at the stator outlet is also shown in Figure 15. At the DE condition, it can be seen that the value of $C v z$ above $40 \%$ span almost does not change with the variation of the stator hub clearance. Compared with the results at zero clearance, when a small stator hub clearance $(0.25 \tau)$ is introduced, the value of $C v z$ below $20 \%$ span decreases slightly while the value between $20 \%-40 \%$ span does not change, which is consistence with the strengthening of the hub corner separation mentioned in Section 3.3. When the stator hub clearance increases to $0.50 \tau$, the leakage flow increases, and the increased leakage flow is mostly offset by the migrant of the low energy flow near the end wall. As a result, the value of Cvz below $20 \%$ span does not decrease obviously, however, as the hub corner separation is suppressed, the value between $20 \% \sim 40 \%$ span increases distinctly. When the stator hub clearance continually increases to $1.00 \tau$, the leakage flow gets a further increment, as the leakage flow in the $0.50 \tau$ case is already enough to suppress the hub corner separation, the further increased leakage flow, in this case, will induce a further decrease of $C v z$ below $20 \%$ span while the value between $20 \%-40 \%$ span almost does not change. At the PP condition, the situation is similar to that at the DE condition, while the deterioration of the flow near the hub is much more obvious at $0.25 \tau$ as the hub corner stall occurrs. At the NS condition, the hub corner stall occurs at zero clearance. In this situation, when a small stator hub $(0.25 \tau)$ is introduced, the hub corner stall still exists, but the value of $C v z$ below $50 \%$ span increases slightly, which means that when hub corner stall happens even a small stator hub clearance may be benefit for the flow. When the stator hub clearance increases to $0.50 \tau$, the induced leakage flow successfully eliminates the hub corner stall, so the value of Cvz below 60\% span increases significantly and the main flow region expands from $30 \%$ span $(70 \%$ 100\% span) to $60 \%$ span $(40 \%-100 \%$ span). In this case, though the hub corner stall is eliminated, the hub corner separation still exists. Hence, when the stator hub clearance continually increases (at $1.00 \tau$ ), the value of Cvz below $20 \%$ span will continually decrease, and the value between $20 \%-50 \%$ span will increase.

On the one hand, the decrease of the axial velocity in the corner means the increase of the flow blockage. Figure 16a shows the flow blockage coefficient at the stator outlet, where the blockage 
coefficient is defined in the way given by Gbadebo, et al. [35]. At arbitrary radial position, the blockage is defined as follow:

$$
\text { Blockage }=\left\{\int_{0}^{\delta}\left[1-\frac{V_{z}(r, s)}{V_{z, f s}(r)}\right] d s\right\} / t(r),
$$

where $t$ is the blade pitch, $r$ is the radial position, $s$ is normalized circumferential position, $V_{z, f s}$ is the axial velocity at the edge of the wake, and $\delta$ is the wake width in pitchwise. It can be seen that the tendency of variation of the flow blockage along with the stator hub clearance is just contrary to that of $\mathrm{Cvz}$. On the other hand, the increase of the flow blockage means the decrease of the flow area, and the decrease of the flow area means the acceleration of the flow velocity and the decrease of the static pressure. Hence, when the flow in the hub corner is improved, the flow blockage decreases and the stator static pressure rise increases, as shown in Figure 16b, which can explain the variation of the stator static pressure rise coefficient shown in Figure 12.

Besides, the flow blockage inside the stator passage can also influence the flow inside the rotor. Taking the situation at the NS condition as an example, when the stator hub clearance increases, the flow blockage in the hub corner decreases, at the stator inlet (i.e., the rotor outlet) the axial flow velocity near the hub increases and the axial flow velocity near the tip decreases (as shown in Figure 17). As the rotor outlet relative flow angle almost does not change, at the rotor outlet the relative flow velocity near the hub increases and the relative flow velocity near the tip decreases. Near the hub, the increased relative flow velocity at the rotor outlet results in a decrease in the static pressure rise. Near the tip, the decreased relative flow velocity at the rotor outlet should bring about an increase of the static pressure rise, but the very strong rotor tip leakage flow at the NS condition makes it hard to increase the static pressure rise anymore. As a result, the total static pressure rise decreases with the decrease of the flow blockage in the stator hub corner. That is why the general tendency of the variation of the rotor static pressure rise coefficient along with the stator hub clearance is opposite to that of the variation of the stator static pressure rise coefficient at the NS condition.

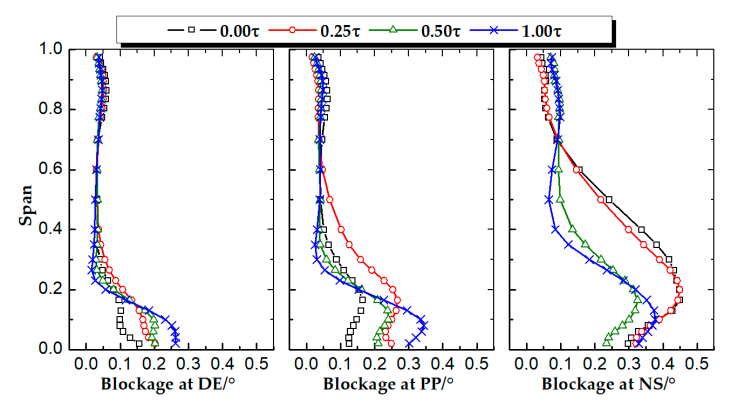

(a) flow blockage at the stator outlet

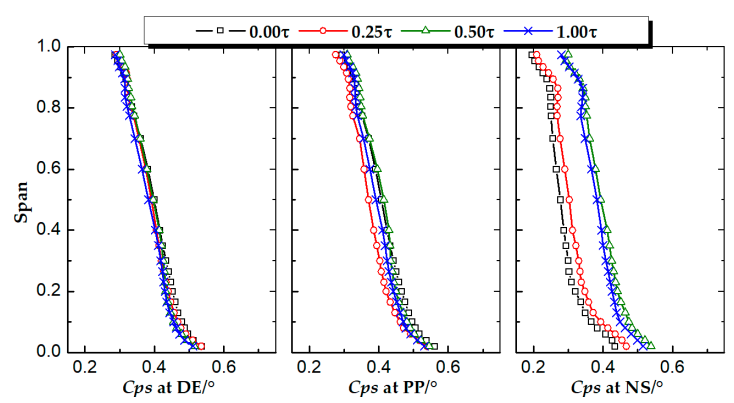

(b) static pressure rise coefficient of the stator

Figure 16. Circumferentially averaged flow parameters of the stator.

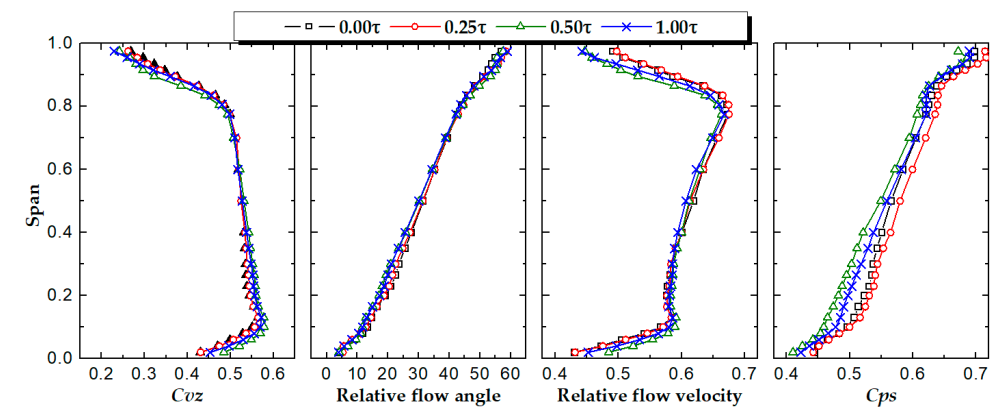

Figure 17. Circumferentially averaged flow parameters at the stator inlet at the NS condition. 
Except for the flow blockage, corner separation/stall can also induce much flow loss. The circumferential averaged distribution of the stator total pressure loss is shown in Figure 18. It can be seen that the variation of the loss with the stator hub clearances is similar to that of the Cvz. At the DE condition, the loss above $40 \%$ span almost does not change with the variation of the stator hub clearance. Compared with the results at zero clearance, when a small stator hub clearance $(0.25 \tau)$ is introduced, the hub corner separation is enhanced, so the loss below $40 \%$ span increases to some extent. When the stator hub clearance increases to $0.50 \tau$, the leakage flow successfully suppresses the corner separation, so the loss between $20 \%-40 \%$ span decreases, and due to the generation of the leakage flow, the loss below $20 \%$ span is still higher than that at zero clearance. When the stator hub clearance increases to $1.00 \tau$, the leakage flow becomes much stronger, so the loss below $20 \%$ span increases compared with that at $0.50 \tau$. At the PP condition, the situation is similar to that of the DE condition. At the NS condition, when the hub corner stall exists, even a small stator hub $(0.25 \tau)$ will decrease the loss, but as the clearance is too small to eliminate the hub corner stall, the loss is still very high. When the stator hub clearance increases to some value $(0.50 \tau)$ the hub corner stall is eliminated and the loss decreases to the minimum. Then, as the stator hub clearance continually increases, the loss will increase. Until now, the flow mechanisms of how the stator hub clearance influence the stator total pressure loss and the stator/rotor static pressure rise have become clear.

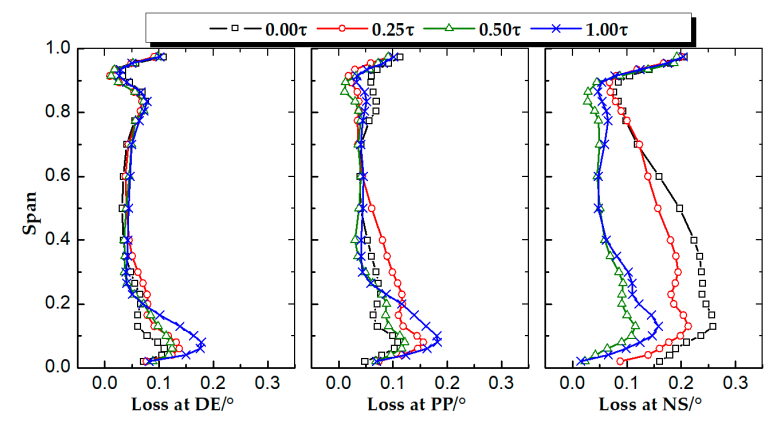

Figure 18. Circumferentially averaged distribution of the stator total pressure loss.

\section{Conclusions}

This paper experimentally investigates the 3D separating flows inside the stator with varied hub clearances of a highly loaded low-speed axial compressor. Measurements including oil-flow visualization, five-hole probe are conducted to reveal the effect of stator hub clearance size on the corner separation and on the compressor performance. Conclusions can be drawn as follows:

(1) At zero clearance, hub corner separation turns into a corner stall as long as the stator incidence is larger than the critical incidence, which makes the compressor performance drop rapidly.

(2) At large mass flow rate conditions (before the occurrence of the hub corner stall), the introduction of a very small stator hub clearance $(0.25 \%$ blade height here) will not improve the hub corner flow, on the contrary, it makes the corner separation more severe and prompts the occurrence of corner stall, which is mainly caused by the fact that the leakage flow has relatively low energy due to the viscosity effect in the clearance and large flow loss generation as the clearance flow comes across and mixes with the transverse secondary flow; when the stator hub clearance increases, the enhanced leakage flow can suppress the transverse migration of the low energy flow near the hub, but excessive leakage flow could induce new mixing loss.

(3) At small mass flow rate conditions (when the corner stall occurs), the hub clearance flow can also suppress the low energy flow to roll into the recirculation region around focus point at the downstream of leading edge on the hub, hence, the strength of the corner stall is diminished even at the very small clearance, and the hub corner stall is eliminated when the hub clearance increases to $0.5 \%$ blade height or bigger. 
(4) As the stator hub clearance varies, there are five typical flow structures in the stator hub corner, namely, Type A, Type B, Type C, Type D and Type E. Type A and Type B correspond to the traditional hub corner separation and corner stall, Type $C$ corresponds to the traditional hub clearance flow, Type D corresponds to the coexistence of the hub leakage flow and the corner separation, and Type E corresponds to the coexistence of the hub leakage flow and the corner stall.

(5) The evolution of the flow topologies inside the stator passage along with the variation of stator hub clearance has an obvious influence on the performance of the compressor, and the flow mechanisms of the effect of the stator hub clearance on the compressor performance is discussed in detail. It is found that there exists an optimum stator hub clearance makes the flow inside the stator to be the most rational and the compressor performance to be the best.

Author Contributions: Conceptualization, B.L.; methodology, Y.Q.; investigation, Y.Q. and G.A.; Writing-Original Draft preparation, Y.Q. and G.A.; Writing-Review and Editing, G.A., Y.Q. and X.Y.; supervision, B.L., X.Y. and G.A.

Funding: This work was supported by the National Natural Science Foundation of China (Grant Nos. 51806004, 51790511) and National Science and Technology Major Project (Grant No. 2017-II-0001-0013).

Conflicts of Interest: The authors declare no conflict of interest.

\section{Abbreviations}

The following abbreviations are used in this manuscript:

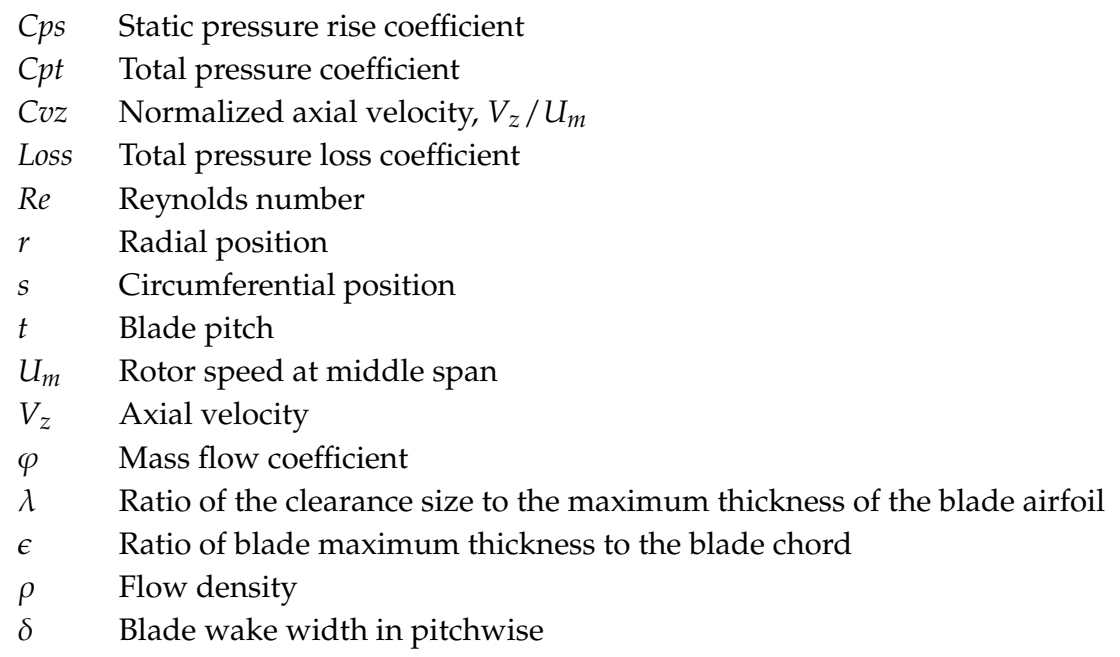

\section{References}

1. Lei, V.M.; Spakovszky, Z.; Greitzer, E. A Criterion for Axial Compressor Hub-Corner Stall. J. Turbomach. 2008, 130, 031006. [CrossRef]

2. Taylor, J.V.; Miller, R.J. Competing Three-Dimensional Mechanisms in Compressor Flows. J. Turbomach. 2016, 139, 021009. [CrossRef]

3. Joslyn, D.; Dring, R. Axial Compressor Stator Aerodynamics. J. Eng. Gas Turbines Power 1985, 107, 485-492. [CrossRef]

4. Schulz, H.; Gallus, H. Experimental investigation of the three-dimensional flow in an annular compressor cascade. J. Turbomach. 1988, 110, 467-478. [CrossRef]

5. Sachdeva, A. Study and Control of Three Dimensional flow Separations in a High Pressure Compressor Stator Blade Row by Boundary Layer Aspiration. Ph.D. Thesis, Ecole Centrale de Lyon, Écully, France, 21 June 2010.

6. Ma, S.; Chu, W.; Zhang, H.; Li, X.; Kuang, H. A combined application of micro-vortex generator and boundary layer suction in a high-load compressor cascade. Chin. J. Aeronaut. 2019, 32, 1171-1183. [CrossRef]

7. Gbadebo, S.A.; Cumpsty, N.A.; Hynes, T.P. Control of three-dimensional separations in axial compressors by tailored boundary layer suction. J. Turbomach. 2008, 130, 011004. [CrossRef] 
8. Peacock, R. Boundary-Layer Suction to Eliminate Corner Separation in Cascades of Aerofoils; Citeseer: London, UK, 1965.

9. Kirtley, K.R.; Graziosi, P.; Wood, P.; Beacher, B.; Shin, H.-W. Design and Test of an Ultra-Low Solidity Flow-Controlled Compressor Stator. In Proceedings of the ASME Turbo Expo 2004: Power for Land, Sea, and Air, Vienna, Austria, 14-17 June 2004; pp. 297-308.

10. Song, Y.; Chen, H.; Chen, F.; Wang, Z. Effects of Air Injection on Performance of Highly-Loaded Compressor Cascades. In Proceedings of the ASME Turbo Expo 2007: Power for Land, Sea, and Air, Montreal, QC, Canada, 14-17 May 2007; pp. 77-86.

11. Nerger, D.; Saathoff, H.; Radespiel, R.; Gümmer, V.; Clemen, C. Experimental investigation of endwall and suction side blowing in a highly loaded compressor stator cascade. J. Turbomach. 2012, 134, 021010. [CrossRef]

12. Hergt, A.; Meyer, R.; Engel, K. Experimental Investigation of Flow Control in Compressor Cascades. In Proceedings of the ASME Turbo Expo 2006: Power for Land, Sea, and Air, Barcelona, Spain, 8-11 May 2006; pp. 231-240.

13. Breugelmans, F.; Carels, Y.; Demuth, M. Influence of dihedral on the secondary flow in a two-dimensional compressor cascade. J. Eng. Gas Turbines Power 1984, 106, 578-584. [CrossRef]

14. Weingold, H.D.; Neubert, R.J.; Behlke, R.F.; Potter, G.E. Reduction of compressor stator endwall losses through the use of bowed stators. In Proceedings of the ASME 1995 International Gas Turbine and Aeroengine Congress and Exposition, Houston, TX, USA, 5-8 June 1995.

15. Dean, R.C. Secondary Flow in Axial Compressors. Ph.D. Thesis, Massachusetts Institute of Technology, Cambridge, MA, USA, 17 May 1954.

16. Lakshminarayana, B. Methods of predicting the tip clearance effects in axial flow turbomachinery. J. Basic Eng. 1970, 92, 467-480. [CrossRef]

17. Lakshminarayana, B.; Horlock, J. Tip-Clearance Flow and Losses for an Isolated Compressor Blade; Aeronautical Research Council London (England): London, UK, 1963.

18. Lakshminarayana, B.; Horlock, J. Leakage and Secondary Flows in Compressor Cascades; HM Stationery Office: Richmond, UK, 1967.

19. Singh, U.K.; Ginder, R.B. The Effect of Hub Leakage Flow in a Transonic Compressor Stator. In Proceedings of the ASME 1998 International Gas Turbine and Aeroengine Congress and Exhibition, Stockholm, Sweden, 2-5 June 1998.

20. Lee, C.; Song, J.; Lee, S.; Hong, D. Effect of a gap between inner casing and stator blade on axial compressor performance. In Proceedings of the ASME Turbo Expo 2010: Power for Land, Sea, and Air, Glasgow, UK, 14-18 June 2010; pp. 203-210.

21. George, K.K.; Sunkara, S.N.A.; George, J.T.; Joseph, M.; Pradeep, A.; Roy, B. Investigations on stator hub end losses and its control in an axial flow compressor. In Proceedings of the ASME turbo expo 2014: Turbine technical conference and exposition, Düsseldorf, Germany, 16-20 June 2014.

22. Gbadebo, S.A.; Cumpsty, N.A.; Hynes, T.P. Interaction of tip clearance flow and three-dimensional separations in axial compressors. J. Turbomach. 2007, 129, 679-685. [CrossRef]

23. Dong, Y.; Gallimore, S.; Hodson, H. Three-dimensional flows and loss reduction in axial compressors. J. Turbomach. 1987, 109, 354-361. [CrossRef]

24. Peacock, R. A review of turbomachinery tip gap effects: Part 1: Cascades. Int. J. Heat Fluid Flow 1982, 3, 185-193. [CrossRef]

25. Sakulkaew, S.; Tan, C.; Donahoo, E.; Cornelius, C.; Montgomery, M. Compressor efficiency variation with rotor tip gap from vanishing to large clearance. J. Turbomach. 2013, 135, 031030. [CrossRef]

26. Wennerstrom, A. Experimental study of a high-throughflow transonic axial compressor stage. J. Eng. Gas Turbines Power 1984, 106, 552-560. [CrossRef]

27. McDougall, N. A comparison between the design point and near-stall performance of an axial compressor. J. Turbomach. 1990, 112, 109-115. [CrossRef]

28. Liu, B.J.; An, G.F.; Yu, X.J.; Zhang, Z.B. Experimental investigation of the effect of rotor tip gaps on 3D separating flows inside the stator of a highly loaded compressor stage. Exp. Therm. Fluid Sci. 2016, 75, 96-107. [CrossRef] 
29. Liu, B.J.; Zhang, S.; Yu, X.J. Experimental investigations on the effects of bowed stator in a highly loaded axial compressor stage. In Proceedings of the 2014 ISFMFE—6th International Symposium on Fluid Machinery and Fluid Engineering, Wuhan, China, 22-25 October 2014.

30. Yu, X.J.; Liu, B.J. Research on three-dimensional blade designs in an ultra-highly loaded low-speed axial compressor stage: Design and numerical investigations. Adv. Mech. Eng. 2016, 8. [CrossRef]

31. Liu, B.J.; An, G.F.; Yu, X.J. Assessment of curvature correction and reattachment modification into the shear stress transport model within the subsonic axial compressor simulations. Proc. Inst. Mech. Eng. Part A J. Power Energy 2015, 229, 910-927. [CrossRef]

32. Everett, K.N.; Gerner, A.A.; Durston, D.A. Seven-hole cone probes for high angle flow measurement Theory and calibration. AIAA J. 1983, 21, 992-998. [CrossRef]

33. Rains, D.A. Tip Clearance Flows in Axial Compressors and Pumps. Ph.D. Thesis, California Institute of Technology, Pasadena, CA, USA, 1954.

34. Zhang, S. Study on the Mechanism of the 3D Blade Design of Highly Loaded Subsonic Axial Compressor. Ph.D. Thesis, Beihang University, Beijing, China, 29 June 2018.

35. Gbadebo, S.A.; Cumpsty, N.A.; Hynes, T.P. Three-Dimensional Separations in Axial Compressors. J. Turbomach. 2005, 127, 331-339. [CrossRef]

(C) 2019 by the authors. Licensee MDPI, Basel, Switzerland. This article is an open access article distributed under the terms and conditions of the Creative Commons Attribution (CC BY) license (http://creativecommons.org/licenses/by/4.0/). 